\title{
Comentarios al análisis del TEPJF al agravio de presunto financiamiento encubierto por conducto de Banco Monex, S. A.
}

\section{Oswaldo Chacón Rojas*}

Sumario:

I. Elementos de contexto y cuestiones a analizar

II. Forma de conducir el análisis por parte del TEPJF

III. Monex 1: Aportaciones privadas prohibidas a través de Frontera Television Network

IV. Monex 2: Financiamiento ilícito destinado a gastos prohibidos

V. Reflexiones finales

* Profesor de Derecho Electoral (UNACH) e investigador nacional. Autor de Dinero del crimen organizado y fiscalización electoral, México, Fontamara, 2011 


\section{Elementos de contexto y cuestiones a analizar}

Debido a la necesidad de transparentar sus procesos democráticos, en la mayoría de los países se han promovido normas para regular el financiamiento y gasto de las campañas electorales. México no ha sido la excepción, pues la regulación del uso y destino de recursos económicos en las campañas siempre ha sido una de las principales preocupaciones del proceso de transición y consolidación de la democracia. Basta señalar que la necesidad de limitar las ventajas económicas del partido gobernante siempre fue una de las principales exigencias de los partidos opositores en las negociaciones de las reformas de la transición. Al principio de dicho periodo, la preocupación medular fue la emisión transparente del voto y su conteo confiable, la expansión del derecho al voto o la garantía de una mejor representación de los partidos opositores en las cámaras. Pero esta dinámica reformista no fue omisa a incorporar reglas con el objetivo de reducir el riesgo de la incidencia del dinero ilícito en procesos electorales. De tal suerte que mediante reformas en 1986-87, 1990, 1993, 1994, 1996 y 2007, así como mediante criterios establecidos en resoluciones jurisdiccionales por parte del TEPJF, se ha consolidado uno de los modelos con mayores regulaciones, restricciones y prohibiciones en el mundo, el cual se acompaña de un organismo autónomo, especializado, dotado de instrumentos de control, verificación y sanción para hacer respetar dichas reglas como es la Unidad de Fiscalización de los Recursos de los Partidos Políticos (UFRPP) del IFE.

Con el establecimiento de este marco regulatorio, el legislador mexicano ha buscado garantizar que en los procesos electorales se privilegie la equidad de oportunidades y la transparencia financiera entre los contendientes. La supuesta violación a estas reglas, constituye el fondo del juicio de inconformidad en comento (SUP-JIN 359/2012).

En efecto, la coalición Movimiento Progresista expuso como causa para declarar la invalidez de la elección de presidente de los Estados Unidos Mexicanos, la vulneración a los principios que rigen los procesos electorales, bajo el argumento que la coalición Compromiso por México, presuntamente había desplegado conductas graves que se apartan de la normatividad de la materia, afectando en forma concreta la libertad del sufragio y la equidad en la contienda, por haber 
utilizado durante la campaña electoral, financiamiento encubierto, paralelo, de procedencia desconocida y prohibido por la ley.

Las supuestas violaciones a las reglas de financiamiento y gasto electoral se desarrollaron a partir de los siguientes hechos:

a) Paquete de publicidad con la empresa estadounidense Frontera Television Networks, para la difusión de imagen y posicionar a EPN en Estados Unidos, a partir de la declaración de José Luis Ponce de Aquino, quien con tal motivo presentó a una demanda el 7 de junio de 2012, en la Corte de Distrito Central de California, Estados Unidos de América, por fraude, incumplimiento de deber fiduciario, falso testimonio, negligencia, incumplimiento de contrato y desagravio por mandato judicial contra Alejandro Ramírez González, director del Consejo de Porcicultores Mexicanos, A. C.; Manuel Gascón, compañías mexicanas GM Global Media, Jiramos y la sociedad civil Servicios Integrales al Sector Agropecuario (SISA).

De la demanda se desprenden los siguientes hechos relevantes al tema a dilucidar.

- Se asegura la existencia de un documento contractual del 28 de noviembre de 2012, entre Frontera Television Network representada por José Luis Ponce Aquino; Jiramos, S.A. de C.V. representada por Alejandro Carrillo Garza Sada y GM Global Media, S. A. de C.V., por conducto de Giselle Moran, señalándose que representó un monto de cincuenta y seis millones de dólares.

- Se dice que existió una transferencia de cincuenta y seis millones de dólares a una cuenta de Jiramos, S.A. de C.V. en Banco Monex, ubicado en Paseo de la Reforma 284, en la Ciudad de México.

- Celebración de un segundo contrato, como consecuencia de haberse "rechazado" el anterior, entre Intelimedia propiedad de José Luis Ponce de Aquino como prestadora del servicio de publicidad, y Servicios Integrales del Sector Agropecuario del Sector Civil por conducto de Alejandro Ramírez González, con la promesa de pago de un anticipo de quince millones de dólares a través de Banco Monex, S.A.

b) Financiamiento a través de Banco Monex mediante la entrega de nueve mil novecientas veinticuatro tarjetas de prepago, que serían distribuidas a la estructura orgánica del Partido Revolucionario Insti- 
tucional — delegados distritales, representantes generales y representantes de casilla-, para compra y coacción del sufragio de los ciudadanos. La accionante hace referencia a la expedición por la referida institución a favor de la mencionada empresa mercantil, de cuarenta facturas por un total de ciento setenta y nueve millones seiscientos treinta y nueve mil seiscientos noventa y tres pesos con setenta y un centavos; facturas de las que se aprecia que fueron emitidas por concepto de "Recompensas Corporativo CARGa DE SALDOS PREPAGo".

c) Financiamiento a través de Banco Monex por Importadora y Comercializadora Efra S.A. de C.V., a quien afirma la accionante le fueron expedidas diversas facturas por la referida institución - sin especificar el monto-, por concepto de "RECOMPENSAS CORPORATIVO CARGA DE SALDOS PREPAGO".

d) Financiamiento a través de Banco Monex por diversas empresas y personas físicas que transfirieron y/o depositaron durante los meses de campaña electoral de 2012, recursos millonarios a dicha institución, que afirma la actora, finalmente fueron parte de las operaciones entre el referido Banco y las empresas Grupo Comercial Inizzio S.A. de C.V. e Importadora y Comercializadora Efra S.A. de C.V.

Las empresas y persona física a que se refiere la coalición Movimiento Progresista son: Comercializadora Atama, S.A. de C.V., Grupo Koleos, S.A. de C.V., Grupo Empresarial Tiguan, S.A. de C.V. y Rodrigo Fernández Noriega (quienes presuntamente efectuaron depósitos y transferencias de procedencia ilícita - lavado de dinero-. Queja Q-UFRPP- 58/2012 y su acumulado Q-UFRPP-246/2012).

e) Como se indicó, la coalición Movimiento Progresista señala que las conductas desplegadas por la coalición Compromiso por México y el Partido Revolucionario Institucional incidieron en el proceso electoral y su resultado, en tanto tuvieron como finalidad la compra y coacción del voto. 


\section{Forma de conducir el análisis por parte del TEPJF}

\section{Criterio de temporalidad}

Uno de los aspectos trascendentales y controversiales de la sentencia, es la decisión del TEPJF de no esperar la conclusión de las investigaciones relacionadas al caso, y realizadas por la UFRPP del IFE con motivo de procedimientos de queja, bajo el argumento de la necesidad de contar con una resolución en la fecha previa a la calificación de las elecciones establecida en la Constitución. Los magistrados sostuvieron que, toda vez que la actora sustentó su impugnación, por un lado, en las investigaciones que el IFE aun se encuentra realizando en las quejas administrativas, a través de las cuales, se denunciaron esos hechos, haría el examen de los planteamientos de la coalición Movimiento Progresista a partir de las pruebas que se encontraban actualmente en autos y las que se hubieran obtenido en el desarrollo de dichos procedimientos $y$, por otro, con base en los hechos expuestos y agravios vertidos al respecto en el escrito de demanda.

En la normatividad se establecen dos procedimientos para la investigación y desahogo de posibles violaciones a las reglas de financiamiento y gasto electoral. Por una parte, la verificación del cumplimiento de las reglas de financiamiento y gasto electoral mediante la revisión de informes financieros presentados por los partidos políticos. Se refiere a la revisión de la contabilidad electoral consistente en la presentación de una contabilidad simplificada de ingresos y gastos de campaña electoral, la cual deberán llevar los partidos, para cada uno de los candidatos que hayan registrado. En México, los partidos políticos deben notificar al IFE quince días antes de la jornada electoral un informe preliminar con los ingresos, egresos y colectas públicas recaudado hasta un mes antes de llevarse a cabo la elección correspondiente. Posteriormente, dentro de los sesenta días hábiles siguientes a la jornada electoral, deben entregar el informe final de sus gastos de propaganda y actos de campaña, dicha obligación se estipula en el artículo 83, inciso $d$, del precitado Cofipe. Tras la presentación del informe, la UFRPP dispone de ciento veinte días para revisarlo, aplicando las pruebas sustantivas y de control que sean necesarias para comprobar la veracidad de lo reportado por los partidos políticos en sus informes. 
Por otra parte, la normatividad contempla un procedimiento de investigación y verificación de cumplimiento a las reglas de financiamiento y gasto electoral derivado de quejas presentadas ante la UFRPP. ${ }^{1}$ El titular de la UFRPP está facultado para ordenar la realización de verificaciones a que haya lugar en relación con las quejas sobre financiamiento y gasto de los partidos políticos; asimismo, podrá solicitar informe detallado al partido denunciado, y requerirle la entrega de información y documentación que juzgue necesaria.

El problema es que los procedimientos de queja también tienen plazos que cumplir, las investigaciones correspondientes deben ser lo suficientemente amplias para acreditar la responsabilidad de los imputados. Implica una tarea compleja, exhaustiva y necesaria para llegar a la verdad legal, soportando las actuaciones en los principios de certeza y legalidad. El plazo otorgado para presentación de los proyectos de resolución no será mayor a 60 días naturales, contados a partir de la recepción de la queja o denuncia por parte de la UFRPP, excepto en los asuntos en que por la naturaleza de las pruebas o de las investigaciones que se realicen, se justifique la ampliación del plazo. ${ }^{2}$ Pero en el desahogo de la investigacion, cada diligencia puede abarcar hasta 30 días naturales, más la notificación de la misma. Esto implica que los plazos para poder realizar una investigación rigurosa y exhaustiva no se corresponden con la necesidad de calificar la elección dos meses después de pasada la jornada electoral. De ahí la decisión del TEPJF de ajustarse a las pruebas que se hubiesen aportado o generado hasta antes del 31 de agosto, que es el plazo legal con el que cuentan para resolver las impugnaciones en torno a la elección presidencial.

Por lo tanto, al momento de calificar la elección presidencial los magistrados no contaron con dictámenes elaborados y votados en el IFE sobre las quejas relacionadas con los recursos de las campañas,

1 La normatividad establece que las quejas sobre financiamiento y gasto de los partidos políticos, serán recibidas por la Secretaría del Consejo General, quien turnará el expediente a la UFRPP. Los quejosos deberán presentar por escrito la queja sobre financiamiento y gasto de los partidos políticos, misma que deberá contener la narración de los hechos que la motivan y aportar los elementos de prueba o indicios con los que cuente el denunciante. Asimismo, es la Dirección de Resoluciones y Normatividad quien se encarga de la elaboración de los proyectos de resolución en relación con el procedimiento administrativo para la tramitación de las quejas y denuncias que se presenten sobre el origen y la aplicación de los recursos derivados del financiamiento de los partidos y agrupaciones políticas.

2 Cofipe, artículo 377 
pero sí con los informes que la UFRPP le rindió al Tribunal para exponer sus consideraciones con motivo del juicio de inconformidad relacionado con la validez de la elección presidencial.

\section{Apego al principio de convencionalidad}

Atendiendo la obligación de que todas las autoridades de nuestro país deben ejercer un control de convencionalidad ex officio, en el desahogo del procedimiento, los magistrados argumentaron que se privilegió el respeto a los preceptos de derecho internacional sobre derechos humanos que consagran los principios esenciales que rigen el debido proceso legal que implica, que toda persona tenga derecho a ser oída en juicio, por tribunales competentes, independientes e imparciales, el derecho a la prueba, al contradictorio procesal, al ejercicio a una defensa eficaz; publicidad de los actos jurisdiccionales, entre otros.

\section{Ordenación cronológica de los hechos}

Con el ánimo de tener mayor claridad y entendimiento de los acontecimientos, el TEPJF desarrolló con acierto el análisis de los hechos y los medios de prueba, a partir del orden cronológico en que se suscitaron. Por una parte, los acontecimientos relacionados con Frontera Television Network, que según el accionante se desarrollaron fundamentalmente en los meses de noviembre y diciembre de 2012, y posteriormente, los vinculados con el financiamiento a través de Banco Monex, S.A. que se suscitaron, según su dicho, en el periodo de la campaña electoral y que trascendieron en actos de movilización para propiciar la compra y coacción del voto, con la consecuente transgresión a los principios rectores del proceso electoral (equidad, certeza, libertad y autenticidad del sufragio, entre otros).

El objetivo de su análisis es establecer si existe o no la vinculación causal que según la actora ha de existir entre los dos hechos y, en un segundo momento, ponderar si los hechos que estén acreditados pudieran encontrar un vínculo causal; esto es, si el quebrantamiento de un principio del proceso electoral puede producir de manera directa la afectación a otro postulado del propio orden constitucional. 


\section{Monex 1: aportaciones privadas prohibidas a través de Frontera Television Network}

Las reglas de financiamiento, es decir, la regulación del flujo de recursos económicos hacia la actividad política, son consecuencia de la multiplicidad de los riesgos en que la corrupción puede llegar a la política. Lo anterior ha conducido a que la mayor parte de los países prohíban y regulen cuidadosamente ciertas formas de financiamiento de manera "positiva" o "negativa".

Las regulaciones "positivas” se expresan a través de financiamiento público, financiamiento privado o, mixto, que es la fórmula que predomina en el mundo. El financiamiento público comprende diversas formas de subvención, tanto directas (en dinero o bonos) como indirectas (servicios, beneficios tributarios, capacitación, etcétera). Se suele otorgar financiamiento público electoral buscando fundamentalmente cuatro cosas:

a) Reducir la dependencia de los candidatos con respecto a los grandes donantes.

b) Nivelar la competencia electoral.

c) Promover la transparencia en el financiamiento del gasto electoral.

d) Incentivar gastos en áreas de interés público. ${ }^{3}$

En México el financiamiento público es proporcionado por el Estado a través del IFE, y consiste en dinero entregado directamente a cada instituto político, para cubrir los gastos de las actividades ordinarias permanentes, para sufragar las actividades extraordinarias de consecución del voto, o como una prerrogativa en cuanto a servicios, infraestructura, exenciones, acceso a los medios de comunicación. ${ }^{4}$

${ }^{3}$ Cabe advertir que ningún país cuenta exclusivamente con financiamiento público electoral. Esto es, los países que contemplan ese tipo de financiamiento, lo acompañan de la posibilidad de allegarse de aportaciones privadas. En consecuencia, la mayor parte de los países se adscribe al modelo de financiamiento mixto.

4 El monto del financiamiento público anual para el sostenimiento de las actividades ordinarias permanentes se determina multiplicando el número total de ciudadanos inscritos en el padrón electoral, a la fecha de corte de julio de cada año, por el sesenta y cinco por ciento del salario mínimo diario vigente para el Distrito Federal. El presupuesto del 
A pesar de que en México se cuenta con una de las fórmulas más generosas para calcular el monto del financiamiento público a los partidos, la normatividad también contempla la posibilidad para que éstos y sus candidatos puedan obtener fondos privados adicionales para financiar sus actividades de campaña. Esta modalidad de financiamiento, es decir, aquel que no proviene de las arcas públicas, se suele regular para evitar dos situaciones: presiones de los donantes hacia los candidatos para que las políticas públicas favorezcan sus intereses particulares, a veces en desmedro del bien común y presión por parte de los candidatos y partidos políticos para que los individuos realicen donaciones en su favor, ya sea extorsionándolos u ofreciéndoles prebendas públicas.

Este mecanismo de obtención de recursos, generalmente se encuentra regulado a través de límites o restricciones en diferentes grados de aportes a distintas personas físicas y morales. ${ }^{5}$ Las restricciones más comunes en la mayoría de los países son: aportaciones de $a$ ) intereses extranjeros $(68 \%) ; b)$ fuentes anónimas (55\%), y c) recursos del Estado ( $85 \%$ de los países estudiados). Muchos países también prohíben aportaciones de las empresas con participación estatal parcial o con contratos del gobierno (46\%). Además de prohibiciones totales a ciertos tipos de aportaciones, en la normatividad internacional encontramos aportaciones que si bien son válidas están sujetas a límites

año 2012 para actividades ordinarias permanentes fue de $\$ 3361120841.57$ (Tres billones, trescientos sesenta y un millones, ciento veinte mil ochocientos cuarenta y un pesos 57/100 M.N.). El financiamiento público anual que resulte de la aplicación de la fórmula ya descrita, se reparte conforme a las siguientes reglas: $30 \%$ del total se entrega de manera igualitaria a los partidos, y 70\% según el porcentaje de la votación nacional emitida que hubiese obtenido cada partido político en la última elección. En cada renovación del Poder Ejecutivo y de ambas cámaras, se asigna un monto equivalente al 50\% del financiamiento público para actividades ordinarias permanentes que le correspondan en ese año. Por ejemplo, para el proceso electoral 2012, los fondos destinados y acordados por unanimidad por el Consejo General del IFE, fueron de \$5344875635.00 (Cinco billones, trescientos cuarenta y cuatro millones, ochocientos setenta y cinco mil seiscientos treinta y cinco pesos 00/100 M.N.) de los que \$1361 120841.57 pesos corresponden al financiamiento público para las actividades ordinarias permanentes.

${ }_{5}$ Puede consultarse el estudio comparativo de financiamiento electoral que abarca distintos países, en: Delia Ferreira Rubio (ed.), Financiamiento de partidos políticos, Buenos Aires, Centro Interdisciplinario de Estudios sobre el Desarrollo LatinoamericanoKonrad Adenauer Stiftung, 1997; Pilar del Castillo y Daniel Zovatto (eds.), La financiación de la política en Iberoamérica, San José, Costa Rica, Instituto Interamericano de Derechos Humanos, 1998. 
cuantitativos. Los más comunes son: $a$ ) los límites de la cantidad que un donante puede dar a un partido político durante un período de tiempo determinado (normalmente un año); $b$ ) los límites a las donaciones permitidas en una elección, y c) los límites a las donaciones que se hagan a los candidatos.

El sistema mexicano contempla financiamiento electoral de origen privado, el cual comprende: $a$ ) aportaciones de los militantes y cuotas voluntarias de los propios candidatos a sus campañas; $b$ ) aportaciones de simpatizantes; $c$ ) autofinanciamiento, y $d$ ) rendimientos por fondos bancarios. La suma o el tope de financiamiento privado que cada partido puede obtener anualmente de los recursos provenientes de las fuentes señaladas y los obtenidos mediante colectas realizadas en mítines o en la vía pública, no podrá ser mayor al $10 \%$ anual del monto establecido como tope de gasto de campaña para la elección presidencial inmediata anterior. Este tope de financiamiento privado incluye tanto aportaciones en dinero como en especie. Asimismo, el financiamiento privado nunca puede ser mayor al financiamiento público.

De acuerdo a la parte promovente, la coalición del PRI-PVEM violentó estas disposiciones normativas, específicamente la prohibición a personas morales con fines mercantiles de hacer aportaciones económicas a las campañas, y los topes a las aportaciones privadas.

\section{Cronología de los hechos y actuaciones}

a) La coalición enjuiciante sostuvo que el 28 de noviembre de 2011, se pretendió firmar un contrato entre Frontera Television Network, representada por José Luis Ponce de Aquino; Jiramos, S.A. de C.V., representada por Alejandro Carrillo Garza Sada, y GM Global Media S.A. de C.V., por conducto de Giselle Morán, para difundir y posicionar la imagen de Enrique Peña Nieto en los Estados Unidos de América, que cubriría el periodo del 15 de enero al 15 de junio de 2012, por la cantidad de cincuenta y seis millones de dólares, ante la presencia de los hermanos José Carrillo Chontkowsky, Alfredo Carrillo Chontkowsky y Roberto Calleja, recursos que recibirían del Estado de México.

b) Que el 6 de diciembre de 2011, Alejandro Carillo Garza Sada, José Carrillo Chontkowsky y Alfredo Carrillo Chontkowsky informaron a José Luis Ponce de Aquino que las personas que financiarían el con- 
trato de publicidad, así como David López Gutiérrez (coordinador de Comunicación Social de Enrique Peña Nieto) y Erwin Manuel Lino Zárate - secretario particular del otrora candidato-, habían rechazado el contrato con la empresa Frontera Television Network, motivo por el cual, solicitaron la firma con otra empresa, denominada Intelimedia, S.A. de C.V. cuyo propietario es José Luis Ponce de Aquino, como prestadora del servicio de publicidad y como adquiriente del servicio Alejandro Ramírez González (señalado como director del Consejo de Porcicultores Mexicanos, Asociación Civil) y la persona jurídico colectiva Servicios Integrales al Sector Agropecuario Sociedad Civil (SISA).

c) El 6 de enero de 2012, José Luis Ponce de Aquino firmó un nuevo contrato, ahora mediante su empresa Intelimedia, S.A. de C.V. y la sociedad civil Servicios Integrales al Sector Agropecuario S.C. (SISA), dirigida por Alejandro Ramírez González de la Confederación de Porcicultores Mexicanos A.C., porque Alejandro Carrillo le informó que Hugo Vigues daría dinero en apoyo al candidato, pero no lo podría entregar si los contratos salían a nombre de Frontera Television Network. En ese acto, se prometió un primer pago que sería de quince millones de dólares a través de Banco Monex, S.A. en los cinco días siguientes a la firma del contrato, lo que no ocurrió, concluye.

d) José Luis Ponce de Aquino afirmó haber presenciado entre el 1o. y 8 de diciembre de 2012, la transferencia bancaria de supuestas cuentas con dinero de procedencia desconocida, radicadas en bancos de Italia, Israel, Portugal o Brasil, a una cuenta de la sucursal de Banco Monex, en Paseo de la Reforma 284, México, Distrito Federal a nombre de Jiramos, S.A. de C.V., por cincuenta y seis millones de dólares, lo cual sucedió a petición de la garantía de pago de los servicios contratados y del otorgamiento de las fianzas correspondientes y también refiere haber conocido de saldos de tres cuentas bancarias de Alejandro Carrillo Garza Sada, en Banco Monex, S.A.

Que posteriormente, recibió promesas de cumplimiento del contrato y el uno de marzo, por medio del representante de sus empresas, Francisco Javier Torres González, exigió la entrega de los contratos, recibiendo como respuesta "la imposibilidad de regresar los documentos solicitados", porque los mismos habían sido utilizados para justificar la salida de recursos del gobierno del Estado de México. Le 
hacen saber que no harán entrega de los contratos porque ya habían sido "ingresados", sin que le hubiesen precisado a dónde.

e) La reseña de José Luis Ponce de Aquino se basa en hechos que se pusieron de manifiesto en el noticiero que conduce la periodista Carmen Aristegui, así como en el periódico Reforma, medios de comunicación en los que se informó de las declaraciones de José Luis Ponce de Aquino, presidente de la empresa estadounidense Frontera Television Network (FTN) e Intelimedia, S.A. de C.V.

En ese programa, sostiene el declarante, se aportaron una serie de indicios que desde su perspectiva, conducen a estimar que los servicios de publicidad que ofrece dicha persona en Estados Unidos de América fueron utilizados para encubrir la obtención, transferencia y manejo de fondos financieros para la campaña de Enrique Peña Nieto, por un monto de cincuenta y seis millones de dólares, de procedencia desconocida, pues firmó un contrato con Alejandro Carrillo Garza Sada, socio de Jiramos, S.A. de C.V., para difundir y posicionar la imagen del aludido candidato.

f) A su vez, Eduardo Sánchez, vocero del Partido Revolucionario Institucional confirmó que en noviembre de 2011, miembros del Partido Revolucionario Institucional - sin especificar nombres- recibieron de Alejandro Carrillo Garza Sada una propuesta de compra de publicidad en los Estados Unidos de América, que refiere haber rechazado. Por otra parte, coincide en que Francisco Javier Torres González a nombre de José Luis Ponce de Aquino requirió al Partido Revolucionario Institucional - sin especificar nombres - un pago de cinco millones de dólares, dando como fecha límite de pago el cuatro de mayo de dos mil doce, amenazando con realizar un escándalo. También, reconoce que pertenecen al Partido Revolucionario Institucional y a la campaña de Enrique Peña Nieto, los involucrados Erwin Manuel Lino Zárate (secretario particular de Enrique Peña Nieto), David López Gutiérrez (coordinador de comunicación social de Enrique Peña Nieto) y Roberto Calleja (secretario de prensa del Partido Revolucionario Institucional).

Sostuvo que Alejandro Carrillo Garza Sada, proporcionó a José Luis Ponce de Aquino, los números de cuenta ABA0210089 de City Bank en Nueva York y 36923384 de Banca Monex, para el depósito de gastos notariales de protocolización de los citados contratos. 
g) Alejandro Ramírez González, que se ostenta como director de la Confederación de Porcicultores Mexicanos, sostuvo que no hay prueba evidente de que haya realizado un contrato por 15 (quince) millones de dólares, que los contratos no están notariados, que sin razón la demanda en su contra se presenta en Estados Unidos y no en México. Afirma que existe una copia de lo que denominó contrato de asociación celebrado por los señores Alejandro Carrillo Garza Sada, Francisco Javier Torres González, José Luis Gutiérrez Miranda, Manuel Gascón Hurtado y José Luis Ponce de Aquino, del 16 de diciembre de 2011, en el cual, aparece solamente la firma del mencionado José Luis Ponce de Aquino y una que se atribuye a José Luis Gutiérrez Miranda. Como sustento esencial de sus afirmaciones, la parte actora ofrece el que denominó: "Contrato de Asociación celebrado entre los señores Alejandro Carrillo Garza Sada, Francisco Javier Torres González, José Luis Gutiérrez Miranda, Manuel Gascón Hurtado y José Luis Ponce de Aquino", del 16 de diciembre de 2011, en el cual, se relaciona la persona moral denominada Jiramos, Sociedad Anónima de Capital Variable.

h) Derivado de la queja -UFRPP 42/2012 y su acumulada Q-UFRPP 43/2012, presentadas por el PAN y el PRD el 14 y 16 de junio respectivamente, la UFRPP requirió información mediante oficios a la Comisión Nacional Bancaria y de Valores; al director general del Registro Público de la Propiedad y del Comercio del Distrito Federal, al Servicio de Administración Tributaria; al director de Auditoría de Partidos Políticos, Agrupaciones Políticas y otros; a José Luis Ponce de Aquino, Evangelina Jiménez Acosta, Mario Gabriel Morán Sánchez, Alejandro Ramírez González, y Alejandro Carrillo Garza Sada información relativa a los hechos investigados (fs. 9289 y a 9291).

i) Las pruebas aportadas por la coalición Movimiento Progresista con relación a esos hechos en la demanda fueron:

A.- Disco compacto que contiene entrevista realizada el 14 de junio de 2012, a José Luis Ponce de Aquino por la periodista Carmen Aristegui, en el programa de radio "Primera Emisión" de MVS.

B.- Documento denominado "contrato de asociación", que tiene en su texto, como fecha de celebración, el dieciséis de diciembre de dos mil once, entre José Aquino - precisando que también acostumbra usar el nombre de José Luis Ponce de Aquino-y José Luis Gutiérrez 
Miranda. En el aludido documento, aparece, que tendría por objeto efectuar una campaña publicitaria para promocionar en Estados Unidos de América, al candidato del Partido Revolucionario Institucional.

C.- Contrato de prestación de servicios celebrado el 6 de enero de 2012, entre Intelimedia, S.A. de C.V., por conducto de José Luis Ponce de Aquino, quien manifestó que también acostumbra usar el nombre de José Aquino, así como de Francisco Javier Torres González y Servicios Integrales al Sector Agropecuario, Sociedad Civil, a través de Alejandro Ramírez González.

\section{Valoración judicial de las pruebas}

Las pruebas de la demanda hacen alusión al programa de radio que conduce la periodista Carmen Aristegui, en la estación MVS radio y también, se dijo que tuvieron difusión en el periódico Reforma. La entrevista aludida dio a conocer los hechos que ahora integran la materia esencial de la investigación, que se practica en las quejas QUFRPP/42/2012 y su acumulado Q-UFRPP/43/2012.

Desde la perspectiva de la parte denunciante, el contenido y la forma como se desarrolló la entrevista, permite derivar indicios de que tuvieron lugar diversas gestiones vinculadas con la contratación de un paquete de publicidad para la difusión de imagen de Enrique Peña Nieto en los Estados Unidos de América.

Según lo expresó la coalición enjuiciante, los acontecimientos que revelan las pruebas aportadas, tienen el alcance probatorio incluso para demostrar el rebase del tope de gastos de campaña, que se llevó a cabo a través de financiamiento encubierto de "procedencia desconocida", por la cantidad de cincuenta y seis millones de dólares.

Al respecto, la Sala Superior recordó que a través de diversas decisiones jurisdiccionales ha reconocido a las notas periodísticas un valor probatorio indiciario respecto de los hechos a los que están referidos. Los reportajes, entrevistas así como los programas de radio y televisión deben ser un cauce de comunicación importante que fomente una opinión pública libre e informada en términos del artículo 6o. de la Constitución Política de los Estados Unidos Mexicanos.

Sin embargo, los magistrados argumentaron que el peso que puede otorgarse a los contenidos de un programa de radio, depende de la ponderación particular que de ellos haga el juzgador, para lo cual, se 
debe tomar en cuenta diversas características de la información difundida, y por supuesto, del soporte de investigación que le precede. En ese sentido, la entrevista, como cualquier otro elemento indiciario, exige un ejercicio de concatenación con otros elementos de prueba que obren en el sumario, para efecto de dilucidar si de un enlace lógico y armónico es posible arribar a partir de un hecho conocido a la demostración de un hecho desconocido. ${ }^{6}$ Luego entonces, la Sala Superior decidió que para dilucidar la certeza de los hechos que sustentan el planteamiento de José Luis Ponce de Aquino, respecto a acontecimientos vinculados con un financiamiento de recursos de procedencia desconocida que tenían por objeto un esquema de publicidad para la campaña de Enrique Peña Nieto, expresados a la periodista Carmen Aristegui, confrontar materialmente la entrevista con las pruebas allegadas y, en general, las pruebas con que se contaba para decidir, para en su caso, encontrar la adminiculación necesaria para corroborarlos, o bien, para determinar que no encuentran soporte respecto de su veracidad, llegando a las siguientes conclusiones:

I) Obraba en autos, un documento que se calificó como contrato de prestación de servicios, fechado el 28 de noviembre de 2011 — carente de firmas- y un diverso documento de rescisión del mismo, del 6 de diciembre de 2011. Este documento fue exhibido en la queja Q-UFRPP 42/2012 y su acumulada Q-UFRPP43/2012 por Giselle Morán, representante de GM Global Media. En el propio ofrecimiento que ella y su hermano hicieron, precisaron que dicho documento no pudo llevarse a cabo, porque no se firmaron los anexos, no se otorgó el anticipo, no se exhibió la fianza pactada y no se prestó el servicio, motivo por el cual, por así convenir a sus intereses, una semana después, el 6 de diciembre se rescindió.

Este documento carente de firmas y el diverso en que consta su rescisión, tienen alcance demostrativo únicamente para apoyar la versión de José Luis Ponce de Aquino exclusivamente en cuanto a que se rechazó un acto contractual en esa oportunidad, esto es, el 28 de noviembre de 2011, pero también tiene un alcance suficiente para poner de relieve que dicha pretendida contratación no consolidó, por

6 Sirvió de apoyo la jurisprudencia 38/2002, NotAs PERIODÍsticas. Elementos PARA DETERMINAR SU FUERZA INDICIARIA, Compilación 1997/2012. Jurisprudencia y Tesis en Materia Electoral, Jurisprudencia, cit., p. 422. 
lo que ese documento, no tiene la eficacia probatoria para generar o representar un acuerdo entre Frontera Television Network y las empresas GM Global Media, S.A. de C.V. y Jiramos, S.A. de C.V., sobre todo, porque del convenio de terminación de servicios profesionales no puede traer como consecuencia que se establezca que hubo contrato con todas sus consecuencias.

De esa guisa, el documento antes referido, no puede servir para apoyar de alguna manera la versión que expone la coalición actora en su argumentación, porque no resulta útil para probar que se haya llevado a cabo, efectivamente, un acto de contratación de un paquete de publicidad para la campaña de Enrique Peña Nieto en los Estados Unidos de América.

II) Por otra parte, de las constancias que obran en autos, resalta un documento que fue exhibido por el propio Camerino Eleazar Márquez Madrid, tanto en el expediente relativo a la queja QUFRPP42/2012 y su acumulada QUFRPP43/2012, así como en el presente expediente del juicio de inconformidad - el cual fue exhibido sólo en copia simple (fs. 2952 a 2957, tomo VI, del presente juicio de inconformidad) - un "contrato de asociación" y que en su texto pretendió hacer referencia a que lo celebrarían los señores Alejandro Carrillo Garza Sada, Francisco Javier Torres González, José Luis Gutiérrez Miranda, Manuel Gascón Hurtado y José Luis Ponce de Aquino, pero que en su calce, sólo lleva rasgos gráficos en los nombres de José Luis Ponce de Aquino - declarante ante los medios de comunicación sobre el hecho aducido- y por José Luis Gutiérrez Miranda, pero sin que obren las firmas de las demás personas, esto es, Alejandro Carrillo Garza Sada, Francisco Javier Torres Miranda y Manuel Gascón Hurtado. No debe dejarse de lado, que en algunos fragmentos de su texto, el documento tiene espacios vacíos, lo que denota, que no puede clarificar cuál era la intención completa y concreta del pretendido acuerdo de voluntades respecto de todas las partes que se precisaron como contratantes.

En razón de lo anterior, el documento en cuestión no tiene la entidad probatoria suficiente para que, de un ejercicio adminiculado con la entrevista multicitada o algún otro medio de convicción que obra en autos, pudiera determinarse la veracidad de la reseña de los acontecimientos en que la coalición actora sustenta su planteamiento de nulidad. 
III) Asimismo, respecto al diverso documento consistente en el contrato de prestación de servicios de promoción (publicidad) que obra en autos, que en su texto señala que fue celebrado entre José Luis Ponce de Aquino, en representación de Intelimedia, S.A. de C.V. y Alejandro Ramírez González como representante de Servicios Integrales al Sector Agropecuario, Sociedad Civil, no se desprende algún dato respecto de alguna transferencia que se haya llevado a cabo entre el 1o. y 8 de diciembre de 2011, ni tampoco respecto a que se hubieran recibido promesas de cumplimiento del contrato ni de que el 1o. de marzo Francisco Javier Torres González haya recibido una respuesta de imposibilidad para regresar los contratos solicitados, porque los mismos habían sido utilizados para justificar la salida de recursos del gobierno del Estado de México, entre otros hechos que no pueden derivarse de los documentos precisados. En ese sentido, tampoco hay evidencia de que el Partido Revolucionario Institucional hubiera realizado alguna transferencia o pago a través de Monex, a las personas que refiere José Luis Ponce de Aquino.

De acuerdo a la Sala Superior, es factible concluir que con los elementos que se tiene para decidir; esto es, del estado que guarda el expediente enviado por la UFRPP del IFE, no se advierten elementos que corroboren la reseña de acontecimientos que narró la coalición actora en su demanda, en lo tocante a que se hayan pactado cincuenta y seis millones de dólares por un paquete de publicidad para promocionar la imagen de Enrique Peña Nieto en los Estados Unidos de América, y tampoco se puede establecer vinculación entre la referida empresa y el Partido Revolucionario Institucional.

\section{Monex 2: financiamiento ilícito destinado a gastos prohibidos}

Según se observa en la sentencia SUP-JIN-359/2012, la coalición actora consideró que además de violaciones a las reglas del origen del financiamiento electoral ya comentadas, la Coalición PRI-PVEM que postuló la candidatura de Enrique Peña Nieto realizó conductas violatorias de las disposiciones en materia de gasto electoral, específicamente gastos a actividades prohibidas como es la compra y coacción de votantes, así como rebase a los topes de gasto establecidos para la contienda. 
El marco regulatorio de la relación entre el dinero y las campañas electorales no se reduce al establecimiento de reglas sobre el origen de los recursos, sino que suele regularse el cómo, en dónde y hasta qué montos pueden gastar los partidos y candidatos. Las regulaciones sobre egresos o gastos electorales, tienen el objetivo de procurar mayor igualdad en las oportunidades de triunfo electoral entre los contendientes, contener el gasto electoral, reducir la probabilidad de captura de líderes y representantes por parte de intereses privados, y prevenir el financiamiento de la política con dinero ilegal. Generalmente las reglas de gasto se refieren a restricciones en cuanto a los montos que pueden erogarse en determinadas actividades electorales (topes de gasto a rubros específicos), y regulaciones respecto de quién o quiénes pueden gastar en ellas y cómo deben de hacerlo.

En México, los partidos pueden gastar en todo lo concerniente a las actividades electorales. La legislación establece que dichos gastos pueden ser de propaganda, operativos y de gastos de producción de los mensajes para radio y televisión. Los primeros comprenden los realizados en medios impresos (diarios, revistas y similares), bardas, mantas, volantes, pancartas, equipos de sonido, eventos políticos realizados en lugares alquilados, propaganda utilitaria y otros relacionados; por su parte, los gastos operativos comprenden los sueldos y salarios del personal eventual, arrendamiento eventual de bienes muebles e inmuebles, gastos de transporte de material y personal, viáticos y otros similares. Los gastos de producción de radio y televisión corresponden a todas aquellas erogaciones que se realicen como pago de los servicios profesionales, uso de equipo técnico, locaciones o estudios de grabación y producción, así como los demás inherentes a la producción de los spots publicitarios para su difusión en medios masivos.

Las actividades en las cuales encontramos mayores restricciones de gasto, son aquellas relacionadas a la publicidad en medios electrónicos y a la compra de votantes. El uso de la radio y la televisión se limita para fines electorales sólo a los tiempos gratuitos que corresponden por ley al Estado y dispone que su administración será desarrollada en exclusiva por el IFE (apartado A del artículo 41 constitucional). En consecuencia, los partidos políticos en ningún momento pueden contratar o adquirir, por sí o por terceras personas, tiempos en cualquier modalidad de radio y televisión.

Mientras tanto, en el artículo 229 se señala que el tope máximo de gastos de campaña será equivalente al $20 \%$ del financiamiento pú- 
blico de campaña establecido para todos los partidos en el año de la elección presidencial. De acuerdo a lo anterior, en este proceso electoral de 2012, el tope de gastos a presidente de la República fue de: $\$ 67222416.83$ para precampaña y \$336112084.16 para la campaña electoral. ${ }^{7}$

\section{Cronología de los hechos y actuaciones}

a) La coalición actora realizó una relatoría de hechos relacionados con la transferencia de recursos por conducto de diversas empresas y una persona física, así como operaciones económicas posteriores por parte de Grupo Comercial Inizzio, S.A. de C.V. e Importadora y Comercializadora EFRA, S.A. de C.V. que según la coalición accionante ascendieron a $\$ 70815534.00$ (setenta millones ochocientos quince mil quinientos treinta y cuatro pesos en moneda nacional).

Sostuvo que esos recursos se emplearon en tarjetas de prepago que se "distribuyeron" entre operadores del PRI en el territorio nacional, durante los meses del proceso electoral 2012 - lo que incluso, afirma, puede implicar operación con recursos de procedencia ilícita- y que tales hechos tuvieron como objetivo o causa final, el pago de representantes generales que fungieron como verdaderos promotores del voto, activistas o movilizadores en el estado de Guanajuato, pero además, que esa distribución se desarrolló a nivel nacional para favorecer al candidato de la coalición Compromiso por México, Enrique Peña Nieto.

En su planteamiento, la propia promovente menciona que existe prueba documental de que diversas empresas y personas físicas transfirieron y/o depositaron durante los meses de la campaña electoral de 2012, recursos que ascendieron a \$ 250455227.71 (doscientos cincuenta millones cuatrocientos cincuenta y cinco mil doscientos veintisiete pesos con setenta y un centavos en moneda nacional) en Banco Monex, S.A.

Las empresas y persona física que, según su manifestación, realizaron esas operaciones son Comercializadora Atama, S.A. de C.V., Gru-

7 IFE, Comunicado de prensa del 23 de noviembre de 2011. Acuerdo General del IFE, sesión extraordinaria del Consejo General celebrada el 16 de diciembre de 2011 CG434/2011 (presidente), CG435/2011 (senador), CG436/2011(diputados), http://www. ife.org.mx/documentos/proceso_2011-2012/preparacion.html. 
po Koleos, S.A. de C.V., Grupo Empresarial Tiguan, S.A. de C.V. y el ciudadano Rodrigo Fernández Noriega.

Asegura que los recursos transferidos a Monex fueron posteriormente parte de operaciones entre el banco antes citado y Grupo Comercial Inizzio S.A. de C.V. e Importadora y Comercializadora EFRA, S.A. de C.V. por $\$ 70815534.00$ (setenta millones ochocientos quince mil quinientos treinta y cuatro pesos en moneda nacional) facturando a estas últimas diversas tarjetas de prepago y de otra índole.

Pero adicionalmente, menciona que ese financiamiento tuvo una finalidad atinente a que operadores del Partido Revolucionario Institucional utilizaran las tarjetas de Monex para pagar a representantes generales y a promotores del voto en el estado de Guanajuato.

La enjuiciante menciona que se desconoce cuál es el origen de los recursos de las empresas Comercializadora Atama, S.A. de C.V., Grupo Koleos, S.A. de C.V., Grupo Empresarial Tiguan, S.A. de C.V., así como de la persona física Rodrigo Fernández Noriega - quienes asegura, hicieron los depósitos en firme a la cuenta de Monex, a través de SPEI, por conducto de Banco Santander-.

b) Con base en los mismos hechos, la UFRPP había iniciado con anterioridad el procedimiento ordinario sancionador SCG/QPAN/ CG/132/PEF/156/2012, derivado de la denuncia presentada el 25 de junio de 2012, por Rogelio Carbajal Tejada, representante propietario del PAN ante el Consejo General del IFE, mediante el cual, denunció a Enrique Peña Nieto, así como al PRI y al PVEM. Precisó que habían recibido tres tarjetas Monex, por parte de "operadores del PRI", y al efecto señalaron que "tres operadores" presentarían testimonio de la forma como se han entregado esos recursos, quién, cuándo y por qué se entregaron esas tarjetas para la operación del día de las elecciones.

Para explicar el flujo de recursos que se desarrollaron en esa "operación financiera", realizaron una estimativa contable de gasto, indicando lo siguiente: cada delegado distrital por el Comité Ejecutivo Nacional del Partido Revolucionario Institucional - hay trescientos en total-, recibe 60000 pesos mensuales en una tarjeta Monex, por lo que en tres meses de trabajo, los delegados distritales reciben una cantidad de \$54000 000 (cincuenta y cuatro millones de pesos). El PRI ha acreditado 19490 (diecinueve mil cuatrocientos noventa) representantes generales, que reciben $\$ 17500$ (diecisiete mil quinientos pesos) por pago de toda la campaña y “recibirán” \$2500 (dos mil quinientos 
pesos) como bono, lo que importa más de trescientos ochenta y nueve millones de pesos.

Además, hay 143151 (ciento cuarenta y tres mil ciento cincuenta y un) representantes de casilla — tres acreditados por este partido-. En cada casilla hay tres casilleros y cada casillero recibe $\$ 600.00$ (seiscientos pesos) lo que da un total de $\$ 257671800$ (doscientos cincuenta y siete millones seiscientos setenta y un mil ochocientos pesos).

Señalaron que la "entrega de las tarjetas de recompensas" emitidas por Monex configura un acto de proselitismo en tiempo de veda electoral, en razón de que constituyen un medio de entrega de dinero susceptible de convertirse en un instrumento de coacción o compra de voto por parte de los delegados, representantes generales y representantes de casilla del Partido Revolucionario Institucional en los distintos estados de la República, el día de la jornada electoral.

En esa tesitura, el PAN solicitó la instauración de un procedimiento extraordinario de fiscalización por el rebase de gastos de campaña, derivado de la emisión de los \$701 471800 (setecientos un millones cuatrocientos setenta y un mil ochocientos pesos). A la denuncia, se acompañó copia simple de dos tarjetas Monex, identificadas con los números de cuenta 5339870301082191 y 533987030108 2092, así como de las correspondientes copias de las credenciales de elector, expedidas por el Instituto Federal Electoral a los ciudadanos Víctor Hugo Bautista González y Eduardo Aguilar Uribe (f. 2 a 19).

Derivado de la queja, la UFRPP realizó diversas diligencias, interrogatorios, requirió información a la $\mathrm{CNBV}$, tomó declaraciones notariadas, a los ciudadanos Martínez Lerma, Víctor Hugo Bautista González, Eduardo Uribe Aguilar, Martín González García, Mario Ignacio Moreno Balderas, Arcadio Valencia Hernández y José Reyes Villanueva, en los que de manera coincidente aceptaron haber recibido una tarjeta Monex, de parte de un delegado del PRI y que en ellas les hicieron dos (2) depósitos, cada uno por dos mil quinientos pesos (\$2500.00) para viáticos (gasolina y alimentación), ignorando quién llevaba a cabo los depósitos, a cambio de reclutar personal para que fungiera como representantes de casilla el día de la elección (f. 241 a 270).

c) En el mismo tenor, la UFRPP inició procedimientos derivados de la queja QUFRPP 58/2012 y su acumulado QUFRPP 246/2012, presentada el 26 de junio de 2012, por el representante del PAN ante el 
IFE, por presunto rebase de tope de gastos de campaña, contra la coalición Compromiso por México y de su candidato a la Presidencia de la República, Enrique Peña Nieto y solicitó se acumulara al expediente Q-UFRPP-42/2012. Los hechos que manifestó fueron, en esencia, los mismos que en la denuncia que dio origen al procedimiento sancionador ordinario SCG/QPAN/CG/132/PEF/156/2012, referido con anterioridad.

Derivado de dicho procedimiento, la UFRPP requirió declaración a Banco Monex, S.A. El propio 26 de junio de 2012, Jacobo G. Martínez Flores, ostentándose como representante de Banco Monex, S.A. Institución de Banca Múltiple, Monex Grupo Financiero (Banco Monex), dio cumplimiento al requerimiento que le hizo la Comisión Nacional Bancaria de Valores y al efecto señaló lo siguiente:

1. De las tarjetas RECOMPENSA emitidas por Banco Monex, identificadas con los números 5339870301082191 y 533987030108 2092, la empresa contrató los servicios de la empresa que se denomina Grupo Comercial Inizzio, S.A. de C.V.

2. El número de tarjetas emitidas y distribuidas a dicha empresa fue de 9,924 y el monto total de los recursos dispersados asciende a $\$ 70,815,534$. Los recursos dispersados a las tarjetas números 5339870301082191 y 533987030108 y 2092 fueron de \$ 5,000 (cinco mil pesos) en cada una.

La UFRPP requirió información al vocal ejecutivo de la 13 Junta Distrital Ejecutiva en el estado de Guanajuato, a los trescientos consejos distritales, el nombre, domicilio y copia de la identificación de los ciudadanos acreditados por el PRI para fungir como representantes generales y de casilla durante el proceso electoral federal 2011-2012, al Servicio de Administración Tributaria.

d) El 26 de julio de 2012, la denunciante ofreció como pruebas supervenientes cinco (5) tarjetas Monex Lealtad, que afirma, se repartieron en Tabasco. En apoyo de su argumentación, la coalición denunciante relacionó 4891 (cuatro mil ochocientos noventa y un) personas residentes en el estado de Tabasco, que afirma, promovieron el voto a favor de Enrique Peña Nieto, candidato por la coalición Compromiso por México, personas que afirma, se desempeñaron como responsables de "activismo" y "movilización" (RAV), las cuales, recibieron en promedio 4000 pesos, del 15 de mayo al 30 de junio de 2012. Por tan- 
to, asegura que sólo en el caso de Tabasco, la campaña de Peña Nieto ejerció por este concepto, alrededor de veinte millones de pesos.

Añade que las tarjetas Monex Lealtad, del Banco Monex, S.A. Institución de Banca Múltiple, Monex, Grupo Financiero, se entregaron a nivel nacional, y, prueba de ello, es la tarjeta que se exhibió, señalando que se trataba de aquéllas que se entregaron en el Estado de México, siendo ésta igual a las que se concedieron en el estado de Tabasco, entidad federativa en la que hay 1133 secciones electorales, en la que se otorgaron cuatro tarjetas Monex Lealtad por Sección Electoral, por lo que bajo esta premisa, a nivel nacional existen 65000 (sesenta y cinco mil) secciones electorales, por lo que en buena lógica se desprende que se repartieron aproximadamente doscientos sesenta (260) tarjetas Monex Lealtad que costaron más de mil millones de pesos.

e) Pruebas aportadas con relación a estos hechos.

1. Contrato de prestación de servicios del 22 de mayo de 2012, que celebra por una parte, Banco Monex, S.A. Institución de Banca Múltiple, Monex, Grupo Financiero, representado por José Antonio García León y por otra parte, Importadora y Comercializadora EFRA, S.A. DE C.V. (Alcance. Tomo I, f.57 a 62).

2. Contrato de mutuo o préstamo comercial con interés y servicios accesorios celebrado el 2 de mayo de 2012, entre Importadora y Comercializadora EFRA, S.A. de C.V. como mutuante y Comercializadora Atama, S.A. de C.V como mutuaria.

3. Comisión Mercantil. Obra el contrato de 26 de marzo de 2012, celebrado entre Comercializadora Atama, S.A. de C.V, como comitente e Importadora y Comercializadora EFRA, S.A. de C.V. como comisionista.

4. Contrato de mandato. Del 2 de mayo de 2012 que celebran Comercializadora Atama, S.A. de C.V., como mandante e Importadora y Comercializadora EFRA, S.A. de C.V. como mandataria.

5. Contrato de mandato sin representación que celebran por una parte Comercializadora Atama, S.A. de C.V. representada por su administrador único, Ramón Paz Morales, en su carácter de "mandante" y Rodrigo Fernández Noriega, por propio derecho, "como mandatario", cuyo objeto esencial del contrato es que el mandatario realice a nombre y por cuenta de "El mandante" el o los depósitos que resulten necesarios, utilizando la cuenta que "Grupo Comercial Inizzio", S.A. de C.V. tiene abierta en Banco Monex S.A. operaciones que serán rea- 
lizadas por cuenta y orden del mandante para llenar los fines relacionados con la actividad y compromisos contractuales del mandante.

6. Contrato de rendición de cuentas y finiquito, del 8 de agosto de 2012, que celebran por una parte Comercializadora Atama, S.A. de C.V. representada por Ramón Paz Morales como mandante y Rodrigo Fernández Noriega como mandatario.

f) Declaración de la empresa Alkino, Servicios y Calidad S.A. de C.V. En el escrito de comparecencia de la coalición Compromiso Por México, la empresa clarificó su posicionamiento. El posicionamiento concreto que formuló la coalición tercera interesada implica el reconocimiento de diversos hechos:

- Existió un acto de contratación entre el mencionado instituto político y la empresa Alkino, Servicio y Calidad, Sociedad Anónima de Capital Variable.

- El contrato tuvo como objeto un mecanismo de disponibilidad inmediata de recursos monetarios mediante tarjetas de prepago con recursos disponibles para ser utilizados para las personas que indicara el Partido.

- Conforme a la contratación con la empresa denominada Alkino, Servicios y Calidad, S.A., la coalición recibió 7851 tarjetas por un monto de $\$ 66326300.00$ (sesenta y seis millones trescientos veintiséis mil trescientos pesos 00/100 m.n.).

\section{Valoración de las pruebas y conclusiones del TEPJF}

El estudio llevado a cabo por la Sala Superior busca dilucidar primeramente si determinadas empresas fondearon la campaña del PRI a través de las tarjetas Monex y, en segundo término, si éstas fueron utilizadas con el objetivo de comprar y coaccionar el voto de los electores.

Primeramente, cabe señalar que la autoridad encontró dificultades de temporalidad, toda vez que buena parte de las pruebas presentadas estaban siendo investigadas por la UFRPP derivado de procedimientos de queja, los cuales no estaban concluidos en el momento en que la Sala Superior debía valorarlos. Recordemos que el TEPJF estaba obligado a resolver los juicios de inconformidad presentados en contra de los resultados de la elección presidencial, antes de la primera semana 
de septiembre posterior a la elección, a efecto de poder cumplir con los términos constitucionales de calificación de las elecciones. Por lo tanto, al momento de valorar el conjunto de los elementos derivados del presunto fondeo a través de Banca Monex a la campaña presidencial de Peña Nieto, únicamente se contaban con resultados parciales de las investigaciones.

Asimismo, es importante advertir que la Sala Superior decidió analizar las pruebas aportadas por las partes y las generadas por la UFRPP de manera aislada. Se trata de un acierto, pues para poder obtener conclusiones de una concatenación de indicios, éstos deben estar plenamente probados y razonados, a efecto de no afectar la presunción de inocencia del indiciado. Por supuesto que la prueba indiciaria siempre ofrece menor seguridad, y siempre deja un mayor margen de dudas en comparación con la prueba directa, pero siempre debe prevalecer la exigencia de que el juez, para condenar, alcance la plena convicción sobre la culpabilidad del acusado, como garantía del derecho a la presunción de inocencia. Es por ello que los indicios han de estar plenamente probados, no puede tratarse de meras sospecha, pues no es factible obtener conclusiones valederas y fundadas (como exige la presunción de inocencia) con base en indicios cuya constatación es incierta.

Con base en esta metodología, el estudio y valoración aislada de las pruebas indiciarias lleva a la Sala Superior a las siguientes conclusiones:

1) Sí hubo fondeo a través de empresas, pero la licitud del origen de los fondos se acreditará una vez que la UFRPP concluya sus investigaciones. En efecto, existe posicionamiento del Partido Revolucionario Institucional, integrante de la coalición Compromiso por México, en su escrito de comparecencia, en cuanto a que existió un acto de contratación con la empresa Alkino, Servicios y Calidad S.A. de C.V. También implica ese posicionamiento que el contrato tuvo como objeto un mecanismo de disponibilidad inmediata de recursos monetarios mediante tarjetas de prepago con recursos disponibles para ser utilizados para las personas que indicara el Partido. Asimismo, se acredita que se efectuaron operaciones económicas con Inizzio y Efra, que beneficiaron a los operadores del PRI. Sin embargo, la Sala Superior considera que al no haberse acreditado que dichos recursos se utilizaron para coaccionar el voto $y$ afectar los valores propios de la materia 
electiva, no le corresponde pronunciarse en torno a lo relativo a si los recursos cuestionados son de procedencia ilícita, en tanto que ello compete a la UFRPP del IFE.

2) De los elementos probatorios al alcance, no se acredita el financiamiento de empresas como Comercializadora Atama S.A. de C.V., Grupo Koleos, Grupo Empresarial Tiguan y de Rodrigo Fernández Noriega a la campaña del PRI. Sí se reconoce el vínculo de Grupo Comercial Inizzio con Atama S.A. de C.V., pero con los elementos que la Sala Superior tuvo para decidir, no se cuenta con elementos para sostener que Comercializadora Atama S.A. de C.V., Grupo Koleos y Grupo Empresarial Tiguan hayan efectuado depósitos a Banco Monex, S.A. por la cantidad de \$250 455227.71 (doscientos cincuenta millones cuatrocientos cincuenta y cinco mil doscientos veintisiete pesos con setenta y un centavos en moneda nacional).

3) El monto del financiamiento que se tiene acreditado es significativamente menor respecto de lo calculado o presumido por la parte promovente. Con base en las declaraciones y documentos presentados, la Sala Superior concluye que de las tarjetas de la serie correspondiente a las 7851 (siete mil ochocientos cincuenta y un) fueron objeto de la contratación entre el Partido Revolucionario Institucional y Alkino Servicios y Calidad, S.A. de C.V., sólo se reconocen 2578 (dos mil quinientas setenta y ocho) tarjetas Monex; que su entrega se dio en las treinta y un entidades federativas y el Distrito Federal, a través de "enlaces estatales", con quienes se celebraron contratos de prestación de servicios asimilables a sueldos, que su distribución se dio en cinco de esas entidades federativas - Baja California Sur, Guanajuato, Morelos, Oaxaca y Sinaloa- a través de "enlaces distritales", es decir, que la entrega no se dio a la ciudadanía en general. Lo anterior fue ratificado en entrevista por parte de los enlaces del Partido Revolucionario Institucional en esos estados. Es decir, no hay pruebas que acrediten que dichos medios bancarios de pago se hubieran repartido fuera de los estados señalados, de manera generalizada, a cualquier persona que no desempeñara cargo de representante del partido.

La Sala Superior no acepta el uso por parte de la promovente de estimativas de gasto para calcular un gasto nacional con base en gastos acreditados aislados, puesto que considera que los ele- 
mentos probatorios presentados no son suficientes para aceptar la realización de dicho ejercicio. Concluye que con los elementos que se tienen para decidir, no se cuenta con elementos para acreditar que las diversas empresas implicadas hayan efectuado depósitos a Banco Monex, S.A. por la cantidad de \$250 455227.71 (doscientos cincuenta millones cuatrocientos cincuenta y cinco mil doscientos veintisiete pesos con setenta y un centavos en moneda nacional).

4) Se acredita que el recurso movilizado a través de tarjetas Monex se utilizó o se gastó en actividades electorales partidistas amparadas por la normatividad. Recordemos que el planteamiento esencial formulado por la coalición accionante está dirigido a demostrar que el financiamiento desplegado a través de Banco Monex, S.A. consistió en que se efectuaron operaciones económicas con Grupo Comercial Inizzio, S.A. de C.V e Importadora y Comercializadora EFRA, S.A. de C.V. que tuvieron como finalidad esencial, que se llevaran a cabo actos de compra y coacción del voto, por parte de operadores del Partido Revolucionario Institucional en el proceso electoral para la Presidencia de los Estados Unidos Mexicanos 2011-2012. De acuerdo a su argumentación, la aplicación de esos recursos benefició a la candidatura de Enrique Peña Nieto, en tanto que representantes generales del mencionado instituto político fungieron como activistas o movilizadores del voto (RAV), y para ello, se les entregaron tarjetas de prepago Monex.

Sin embargo, los enlaces partidistas entrevistados fueron coincidentes en señalar que recibieron las tarjetas Monex, por concepto de viáticos generados por sus actividades como representantes del partido, esto es, por la prestación de un servicio partidista en los cinco estados señalados. Considerando que lo único con que se cuenta son las declaraciones de los enlaces partidistas, y que no se identifican elementos probatorios suficientes para rebatirlos, la Sala Superior acepta que la entrega de tarjetas Monex a los declarantes, fue para financiar actividades propias a su función como representantes del partido que militan, y no porque hubieran sido contratados para llevar a cabo coacción del voto. La ley electoral precisa que los partidos pueden realizar gastos relacionados a su operación ordinaria, para el sostenimiento de sus órganos directivos y de sus organizaciones, pero también gastos de campaña destinados a financiar actividades para obtener el voto, por 
lo que resulta justificable la entrega de recursos a los representantes de partido para realizar actividades con este fin. Es así que la Sala Superior concluye que no se cuenta con elementos de prueba fehacientes de que quienes recibieron las tarjetas Monex hayan llevado a cabo una función de "movilización" o alguna otra que se tradujera en el influjo o sugestión al electorado. Está acreditada la entrega de tarjetas, pero en autos no hay elementos que permitan advertir que dicha distribución se hizo con objeto de vulnerar la libertad del voto mediante la compra del sufragio a cambio del voto por Enrique Peña Nieto.

\section{Reflexiones finales}

El establecimiento de marcos regulatorios de financiamiento y gasto electoral en el mundo ha sido significativo, tomando en cuenta que hasta hace algunos años en la mayoría de las democracias el tema había sido ignorado. Sin embargo, los avances no han logrado mitigar los retos y cuestionamientos de la ciudadanía ni de los propios actores políticos. Se trata de un tema global, pues diversas agencias internacionales han acreditado que la escalada de conflictos poselectorales relacionados al dinero en las campañas ha ido en aumento. Los cuestionamientos se han presentado independientemente del avance regulatorio en cada país, tanto en aquellos cuyas restricciones y garantías de control son mínimas, como en aquellos que han logrado consolidar un andamiaje de reglas y controles en su normatividad.

En este segundo supuesto se encuentra México, pues las quejas y cuestionamientos al modelo de control de las reglas de financiamiento y gasto electoral fueron una constante en las elecciones presidenciales de 2012, y el argumento principal del juicio de inconformidad presentado contra los resultados de la elección. Del análisis de la sentencia se pueden obtener lecciones y reflexiones importantes para el fortalecimiento del andamiaje normativo.

En primer lugar, se puede observar que los tiempos de la fiscalización de los recursos de las campañas corren en tiempos distintos al proceso de calificación de las elecciones, por lo que dichos procedimientos no aportan los suficientes elementos para la calificación jurisdiccional de la validez de los resultados de las elecciones. Lo anterior resta la posibilidad de un análisis más exhaustivo y profundo 
del cumplimiento de las reglas de financiamiento y gasto electoral al TEPJF. Además, genera incentivos para que partidos y candidatos incumplan con la norma, pues generalmente cuando se llega a detectar y sancionar la conducta violatoria es muy probable que la misma haya rendido los beneficios esperados. Ante ello, quizá sea conveniente incorporar a la normatividad la realización de una fiscalización autoaplicativa inmediatamente después de concluida la jornada electoral, destinada a verificar el cumplimiento de rubros específicos, como por ejemplo el respeto a los topes generales de gasto, a partir de los propios hallazgos obtenidos por la UFRPP en el desarrollo de las campañas, sin necesidad de esperar la entrega formal de informes, y con la obligación partidista de informar sobre sus prorrateos a partir de que sean requeridos.

Por otra parte, se observa que existen evidentes dificultades probatorias para acreditar las violaciones a las reglas de financiamiento y gasto electoral, pues generalmente se trata de actividades encubiertas de las cuales únicamente se pueden obtener pruebas indirectas o indiciarias. En el juicio de inconformidad en comento, además de contratos incompletos, la parte promovente aportó elementos de estas características, como testimonios, notas periodísticas o llamadas telefónicas, que sólo cuentan con valor demostrativo indiciario, por lo que carecen de eficacia probatoria por sí mismas. La debilidad de los indicios presentados, llevaron a la Sala Superior a concluir que no había elementos suficientes para demostrar que se pudieron haber materializado actos de compra y coacción de voto a través de la distribución de las tarjetas Monex.

Ante la dificultad probatoria de las violaciones a las reglas de financiamiento y gasto electoral, quizá sea conveniente transitar a un modelo menos restrictivo, incrementando considerablemente los montos de los topes de gasto y permitiendo en algunas circunstancias las aportaciones de personas morales con fines mercantiles o comerciales. La sobrerregulación en la materia resulta sumamente complicada de hacerla respetar en un juicio, de ahí que se requiera un modelo que no establezca tantas restricciones, que no genere tantos límites y prohibiciones estrictas, para no fomentar la ilegalidad, la simulación, y la pérdida de credibilidad de las instituciones y los procesos electorales.

No hay que tenerle miedo a esta posibilidad. La experiencia mundial nos demuestra que resulta muy complicado hacer respetar en la práctica las restricciones al financiamiento y gasto electoral. En Fran- 
cia y Japón se han aprobado reformas para prohibir la financiación de campañas políticas por parte de las empresas o corporaciones del sector privado, y los resultados no han sido los esperados. Entre más restrictivas sean las reglas de financiamiento más complicado resulta hacerlas valer. Reglas restrictivas solamente tienen éxito en países con regímenes parlamentarios que tienen plazos muy cortos de campaña, pues en consecuencia resultan muy poco exigidas. Pero este no es el caso de sistemas presidencialistas como el mexicano.

Finalmente, se debe reconocer que hay poco por hacer para acreditar los gastos destinados a actividades como la compra de votos. Detrás de la compra-venta del voto se encuentra la regla de la oferta y la demanda, de ahí que la solución a este problema pasa por mejorar las condiciones socioeconómicas del país. Requiere del ataque frontal a las enormes desigualdades socioeconómicas que generan condiciones propicias para la práctica de esta conducta. Requiere generar condiciones para que, a la idea de Rousseau, no haya nadie tan pobre que tenga necesidad de venderse y nadie tan rico que pueda comprar a alguien. El contexto de clientelismo, impunidad, violencia e ineficiencia institucional con un ambiente de apatía y cinismo por parte de los ciudadanos, genera condiciones para que la corrupción se extienda, prospere y se consolide, dificultando cualquier estrategia de control o regulación. Por eso habría que apostar, siguiendo a Ortega y Gasset, a "cambiar los usos más que a combatir los abusos", aunque esto último tampoco sea muy fácil. 